\title{
As estratégias de retórica na disputa pela Prefeitura de São Paulo em 2004: PT, mandatário, versus PSDB, desafiante
}

\author{
Luciana Fernandes Veiga \\ Universidade Federal do Paraná \\ Doxa/Instituto de Pesquisas do Rio de Janeiro \\ Nelson Rosário de Souza \\ Universidade Federal do Paraná \\ Emerson Urizzi Cervi \\ Instituto de Pesquisas do Rio de Janeiro
}

\begin{abstract}
Resumo
A experiência do PT no governo (nos âmbitos nacional e local) suscitou a curiosidade sobre possíveis alterações no seu discurso eleitoral na disputa pela Prefeitura de São Paulo. O foco desta análise está nas continuidades e rupturas das estratégias retóricas elaboradas a partir dos eixos ideológico (esquerda e direita) e pragmático (mandatário e desafiante). A preocupação central é o discurso do PT, e a análise da comunicação apresentada pelo PSDB tem um caráter complementar. Todos os programas e spots veiculados pelas campanhas do PT e do PSDB em São Paulo foram analisados a partir de métodos qualitativos e quantitativos.
\end{abstract}

Palavras-chaves: discurso partidário, Partido dos Trabalhadores, eleições municipais, São Paulo.

\section{Abstract}

The experience of the Worker's Party at the Brazilian national and local governments has estimuladted the curiosity about changings in its electoral discourse at the elections for the São Paulo Mayor. This article focuses on the changes and continuities of rethorical strategieand the analysis is based on campaign 'spots' veiculated by the Worker's Party and the Brazilian Social Democratic Party. 
Key words: party discourse, Worker's Party, local elections, São Paulo. Introdução

Ao longo das duas últimas décadas, os brasileiros se acostumaram com o discurso do Partido dos Trabalhadores, predominantemente de esquerda e oposicionista. As críticas do partido recaíam particularmente na política econômica neoliberal praticada pela seqüência de presidentes desde a redemocratização e suas seqüelas na promoção da justiça social. Em 1989, o então candidato Lula pregava o não pagamento da dívida externa; em 1994 e 1998, ele criticou o Plano Real e, mesmo em 2002, argumentava ser a política econômica do então presidente Fernando Henrique e de seu ministro Pedro Malan, a responsável pelos altos índices de desemprego.

A proposta de um governo participativo era outro aspecto do discurso de esquerda do partido. Nas campanhas do PT, o povo brasileiro era apresentado como uma entidade organizada e cidadã.

Em 2004, aconteceram as primeiras eleições depois que o partido assumiu a Presidência da República. Acompanhar o pleito de 2004 e identificar como a experiência no governo federal pode ter alterado o discurso nos pleitos municipais despertaram a atenção dos pesquisadores do Grupo de Comunicação e Política da Universidade Federal do Paraná ${ }^{1}$.

Em trabalho anterior, (VEIGA, SOUZA e CERVI, 2005) a equipe já analisou os discursos do PT e de seus principais adversários em Curitiba e Porto Alegre. Neste artigo, será realizado o debate sobre São Paulo. A eleição na capital paulista foi particularmente importante porque era considerada como o terceiro pleito da disputa de 2002: era a oportunidade do PT reforçar a vitória obtida na disputa presidencial ou da superação do PSDB com o candidato José Serra. Todo o país acompanhava o desempenho dos dois partidos em São Paulo.

No âmbito municipal, o PSDB também podia ser classificado como desafiante. José Serra concorria com a então Prefeita, Marta Suplicy (PT). Assim, acompanhar o discurso do PT em São Paulo em 2004 era acompanhar o discurso do partido que estava na situação nos âmbitos nacional e local e cuja vitória era muito importante para as duas esferas de poder.

O artigo está organizado da seguinte maneira: em um primeiro momento, a idéia é apresentar uma revisão da literatura sobre os estudos dos discursos eleitorais do PT; o passo seguinte é entender o desempenho e a retórica do partido nas eleições municipais da capital paulista desde 1985; a seguir, serão

\footnotetext{
1 Para o trabalho foi utilizado o arquivo de propagandas eleitorais do Doxa/luperj. Por isso, gostaríamos de agradecer ao Prof. Marcus Figueiredo e à Alessandra Aldé. Agradecemos às bolsistas de iniciação científica Sandra dos Santos, Carolina de Paula e Rossana Freitas da UFPR, que contribuíram muito para a realização do trabalho.
} 
VEIGA, L.; SOUZA, N.R.; CERVI, E.U. As estratégias de retórica na disputa pela prefeitura...

apresentados os dois eixos que norteiam a análise dos discursos: o espectro esquerda e direita e a escala situação e oposição. Interessa entender até que ponto os discursos do PT e do PSDB podem ser diferenciados pensando na escala ideológica de esquerda e direita e, ainda, verificar como o PT elaborou o seu discurso de mandatário e o PSDB construiu a sua retórica de desafiante. O estudo a partir dos dois eixos já foi elaborado anteriormente por Oliveira (2005) ao analisar as disputas municipais de Belo Horizonte e Salvador em 2000.

A quarta parte do artigo traz a análise propriamente dos programas e spots veiculados pelas campanhas do PT e PSDB em São Paulo. Para o estudo da propaganda foi utilizada a mesma metodologia empregada nos estudos anteriores de Curitiba e Porto Alegre. Trata-se de uma adaptação do estudo original de Figueiredo, Aldé, Dias e Jorge (2000), que se empenharam na elaboração de uma metodologia para análise de spots eleitorais. Na conclusão, algumas rápidas considerações sobre o discurso do partido nas três diferentes capitais: São Paulo, Porto Alegre e Curitiba.

1. A trajetória e a retórica do PT: alguns fragmentos de discursos ao longo da história.

Não há a pretensão de fazer um exaustivo levantamento sobre os discursos utilizados pelo PT ao longo de sua história, mas apenas apontar para os aspectos mais centrais dessa trajetória.

Desde a volta da democracia, o PT vem se consagrando como o principal partido de esquerda do país. A primeira experiência eleitoral da legenda foi em 1982, quando o então líder sindical Lula se candidatou ao governo do estado de São Paulo, tendo como um de seus principais lemas: "Vote no três que o resto é burguês".

Discurso semelhante esteve presente na disputa presidencial de 1989. Naquela eleição, Lula tinha como principal adversário Fernando Collor de Mello (PRN), que venceu com um discurso populista e de direita. A campanha de Lula também adotou um enfoque fortemente ideológico, propunha que a exploração da classe trabalhadora pela classe capitalista era o problema fundamental do país e a chegada dos trabalhadores no poder a solução (ALBUQUERQUE,1999). Além dos discursos de classe e de oposição à política neoliberal havia a valorização da sociedade organizada. O discurso do então candidato Lula evidenciava as tendências: 
Enquanto a dona de casa, enquanto o trabalhador se mata pra comprar o seu feijão, se mata pra comprar o que comer diariamente, às custas de uma inflação de quase $40 \%$, aparece na televisão, cinicamente, os empresários e o governo dizendo que são contra a inflação e que querem acabar com a inflação. Mas é exatamente, cenas como estas, do investimento no ouro, do over, aonde este ano 15 milhões de dólares foram lucros para os empresários, saídos do setor público, ou seja, dinheiro do Estado que deixou de ser investido na produção pra ir para os cofres dos patrões. (...) (Discurso de Lula na campanha de 1989, extraído de ALBUQUERQUE, 1999, p. 158).

Ainda que o partido não tenha vencido em 1989, não há dúvidas de que ele obteve um resultado surpreendente. Lula terminou o primeiro turno com mais votos do que políticos tradicionais como Ulysses Guimarães (PMDB), Aureliano Chaves (PFL), Mário Covas (PSDB) e Leonel Brizola (PDT).

Em 1994, o PT passou por uma de suas piores experiências eleitorais. Até meados de maio de 1994, a vitória de Lula parecia certa. O candidato aparecia nas pesquisas de opinião com aproximadamente $42 \%$ dos votos válidos. O então ministro da fazenda Fernando Henrique (PSDB) ficava em segundo lugar com 14\%. Aconteceu, então, o imponderável: o Plano Real. O candidato Lula ficou sem discurso diante do sucesso do plano para estabilização da moeda, implantado pelo ministro do presidente Itamar Franco. Roberto Amaral (1995) descreveu bem o que aconteceu naquele momento: a "campanha ficou paralisada, indo e voltando, atacando um dia e no outro prometendo manter o Real, salvá-lo e aperfeiçoá-lo", sem indicar uma alternativa ao plano.

Pode-se dizer, em linhas gerais, que o partido ao elaborar o seu discurso privilegiou a postura ideológica à pragmática. Preferiu atacar o Plano Real que era mencionado na campanha como mais um ineficiente plano econômico burguês a se ater à satisfação da população brasileira com a economia. Ao longo da campanha houve mudanças na intenção de voto e Fernando Henrique foi eleito já no primeiro turno.

Em 1998, a questão da estabilidade do Real voltou a ganhar centralidade na disputa presidencial. A moeda e o efeito estabilizador da inflação ao longo de quatro anos de vigência eram apreciados por mais da metade do eleitorado. A expectativa de que uma vitória de Lula permitiria o retorno da inflação pode ser vista como uma grande barreira para o crescimento da candidatura do PT. Como aconteceu em 1994, o discurso oposicionista não beneficiava a candidatura de Lula. Para Venturi (1998), as oposições não conseguiram explicar para os cidadãos que o nível de desemprego e a fragilidade do Brasil diante da crise econômica que acometia a Rússia e os Tigres Asiáticos eram decorrência da política econômica de 
VEIGA, L.; SOUZA, N.R.; CERVI, E.U. As estratégias de retórica na disputa pela prefeitura...

Fernando Henrique. Este discurso pautou a campanha de Lula, mas os eleitores não estavam convencidos de sua veracidade e novamente Fernando Henrique foi eleito já no primeiro turno.

Em 2002, o eleitorado estava insatisfeito com a política econômica do segundo governo Fernando Henrique. Ainda em 1999, o presidente desvalorizou a moeda e tal atitude influenciou o padrão de vida dos brasileiros. No caso dos eleitores mais pragmáticos, as frustrações com a economia e as expectativas de mudanças pareciam casar perfeitamente com um discurso oposicionista. No caso dos eleitores mais ideológicos, o cansaço com a política neoliberal do PSDB era a indicação de que se esgotava um ciclo do partido no governo federal.

$\mathrm{Na}$ ocasião, o discurso de Lula estava mais moderado. Antes da disputa, ele assumiu publicamente o compromisso de cumprir contratos assinados com o mercado financeiro internacional, mas ainda assim, mantinha a retórica oposicionista em relação ao PSDB e mais à esquerda.

\section{A trajetória e a retórica do PT nas disputas pela Prefeitura de São Paulo.}

A rivalidade entre petistas e malufistas iniciou-se em 1988 e se estendeu nos pleitos seguintes. A disputa inicial se deu entre Luiza Erundina (PT) e Paulo Maluf (PDS), resultando na vitória da candidata petista. O representante tucano era José Serra, que obteve $6,9 \%$ dos votos. No pleito municipal seguinte, em 1992, Maluf (PDS) se apresentou para a disputa novamente, enfrentando e vencendo Eduardo Suplicy (PT). Fábio Feldman (PSDB) obteve 5,8\%.

Na eleição de 1996, Paulo Maluf indicou seu secretário da Fazenda, Celso Pitta (PPB), para disputar sua sucessão com Luiza Erundina (PT). Graças ao prestígio do padrinho, Pitta (62,3\%) venceu. José Serra, de novo candidato, obteve $15,6 \%$ dos votos.

O PT retorna à Prefeitura de São Paulo quatro anos depois com a vitória de Marta Suplicy sobre Maluf. O então vice-governador Geraldo Alckmin (PSDB) obteve $17,2 \%$ dos votos no primeiro turno.

Ao analisar o pleito de 2000 na capital paulista, Chaia, Meneguello, Azevedo e Schmitt (2002) ressaltaram que os dois principais adversários apresentavam práticas políticas muito distintas com propostas antagônicas para a cidade.

Marta Suplicy (PT) que defendeu uma proposta de gestão com participação, transparência e ética, com divisão da cidade em subprefeituras, com conselhos de representantes e orçamento participativo; de outro lado Maluf (PPB), que retomaria a proposta de administração da cidade de São Paulo da época em que foi prefeito: centralização, não participação da sociedade, administração 
extremamente personalista e com esbanjamento dos gastos públicos, com cooptação da Câmara Municipal e outras práticas políticas nefastas. (CHAIA et al, 2002, p.38)

Ou seja, o antagonismo entre propostas e discursos estava muito claro, de um lado, havia a estratégia conservadora de Paulo Maluf e, de outro, o projeto de esquerda do PT, assim como nos anos anteriores. O eleitorado se via repetidas vezes entre dois medos conhecidos. Por um lado o conservadorismo malufista e a administração da eficiência e, do outro, a esquerda no poder e a administração pela transformação, (CHAIA et al, 2002).

Em 2004, o ciclo de malufismo versus PT foi rompido. Após uma série de denúncias sobre corrupção, desvio de dinheiro e superfaturamento de obras públicas envolvendo Paulo Maluf e seu grupo político, o malufismo foi perdendo espaço entre o eleitorado paulistano. A cada dia parecia mais insustentável o "rouba, mas faz" como argumento de defesa do voto em Paulo Maluf.

Por outro lado, o PT foi reduzindo o tom de esquerda do seu discurso. Após as primeiras denúncias de corrupção no âmbito federal, o partido abriu mão, também, do discurso da ética e da transparência. Além disso, com a saída de Maluf do páreo, a estratégia perdia sua eficiência.

Paulo Maluf se lançou à disputa em 2004, mas sua candidatura ficou em uma situação periférica. A disputa ficou focada em Marta Suplicy (PT) e José Serra (PSDB). O inusitado aconteceu no segundo turno, quando Marta Suplicy aceitou o apoio de Paulo Maluf. Com a desestruturação do antagonismo que marcara as disputas em São Paulo até então, as antigas estratégias discursivas caíram por terra. Como se pretende mostrar, não houve naquele pleito mais lugar para o estereótipo: candidato de direita versus candidato de esquerda. O discurso ficou mais no campo pragmático: situação versus oposição.

\section{A apresentação dos dois eixos de análise}

\section{1) Eixo esquerda e direita}

Ao analisar as retóricas utilizadas nas campanhas de Salvador e de Belo Horizonte, Oliveira (2005) parte de dois eixos de análise - um ideológico e outro pragmático. No eixo ideológico temos a escala esquerda e direita; no eixo pragmático temos as posturas de situação e oposição. Os mesmos eixos analíticos serão utilizados nesse trabalho. A nossa proposição é que as campanhas do PT e do PSDB se diferenciaram menos no discurso ideológico e mais no discurso pragmático. 
VEIGA, L.; SOUZA, N.R.; CERVI, E.U. As estratégias de retórica na disputa pela prefeitura...

Na definição do primeiro eixo é preciso esclarecer os conceitos de esquerda e direita. Nossa definição estará ancorada em três aspectos:

\section{Aspecto 1: 0 ideal de igualdade}

Esta é a principal divisão entre esquerda e direita no debate político. Para Bobbio (1995), a esquerda e a direita se diferenciam quando três perguntas são respondidas: Igualdade entre quem, em relação à que e com base em que critérios? A esquerda estaria disposta a realizar mudanças em busca de mais igualdade, já a direita não estaria disposta a realizar mudanças em prejuízo da ordem.

Em relação ao eleitorado brasileiro, propõe-se - assim como Singer (2002) que ainda que a esquerda seja mais igualitária que a direita, não podemos afirmar que os eleitores de direita sejam contrários à promoção de maior igualdade. A partir de survey desenvolvido por Moisés, Singer mostra que $81,9 \%$ dos eleitores concordam que "em um país como o Brasil, é obrigação do governo diminuir as diferenças entre os muito ricos e os muito pobres".

Em uma sociedade marcada pela profunda desigualdade de renda, como é a brasileira, parece compreensível que vastas porções do eleitorado - elas próprias desvalidas - sejam simpáticas a medidas de cunho igualitarista, independentemente da posição ideológica em que se situem. Devido ao tremendo impacto da desigualdade sobre o conjunto da sociedade, pode-se dizer que o igualitarismo tornou-se espécie de ideologia nacional. (SINGER, 2002, p. 147)

Neste caso, pode se dizer que a postura a favor de maior igualdade social embora seja tradicionalmente destinada à esquerda - é adotada também pelos partidos de centro e de direita no Brasil atual, na medida em que, tal como foi colocado por Singer, tornou-se uma ideologia nacional.

\section{Aspecto 2: Intervenção do estado na economia}

O segundo aspecto envolvendo os conceitos de esquerda e direita se refere ao grau de intervenção do estado na economia. Neste caso, em principio, os partidos podem defender uma postura mais estatizante, caso sejam de esquerda, ou mais neoliberal (privatista), caso sejam de direita.

Estudos recentes sobre a cultura política na Europa demonstram que os públicos de direita e de extrema direita vêm se aproximando da esquerda ao também desejarem maior intervenção do estado na economia. Singer (2002) vai demonstrar que também no caso brasileiro há uma tendência do público de direita em ser estatizante. Ainda citando o trabalho desenvolvido por Moisés, Singer (2002) lembra que ao serem solicitados a reagirem à frase "para que o país cresça, o 
governo deveria intervir mais na economia", os eleitores localizados à direita chegaram a concordar mais do que os eleitores de esquerda.

\title{
Aspecto 3: O ideal da participação popular
}

A partir deste aspecto, pode-se propor que a direita tende a adotar uma postura mais hierárquica, desejosa de reforçar a autoridade repressiva e ao mesmo tempo provedora do Estado. Ou seja, ela tem uma atitude que defende a manutenção da ordem na busca por maior igualdade. Para isso, os direitos sociais precisam ser providos, mas de cima para baixo. Já a esquerda defende e aposta na mobilização social como meio de obter direitos sociais para todos. Para Singer (2002), esta é a clivagem mais forte entre os dois pólos ideológicos no Brasil.

\begin{abstract}
A diferença entre esquerda e direita no que diz respeito à mobilização social explicita-se ainda na resposta à seguinte questão da pesquisa Cultura Política/90: "O que seria melhor para resolver os problemas do Brasil: 1. a atuação de um líder que colocasse as coisas no lugar; 2. ou a participação da população nas decisões importantes de governo, 3. ou as duas coisas" Enquanto $65 \%$ dos eleitores de esquerda preferem a participação, essa opção só é adotada por $48 \%$ dos eleitores que se colocaram à direita. (SINGER, 2002).
\end{abstract}

Como já foi mencionado anteriormente, o discurso do PT nas disputas presidenciais sempre abordou os efeitos do neoliberalismo, sobre a necessidade de se promover maior justiça social e a importância de dar espaço e promover a mobilização social. De acordo com Chaia et al (2002) em São Paulo o PT também tratou de tais clivagens de modo a se diferenciar de Paulo Maluf em 2000. E como o PT se comportou em 2004?

\section{2) Eixo situação - oposição}

Figueiredo et al (2000) propõem que em sua forma mais simples, o jogo da persuasão em uma disputa tem a seguinte estrutura: a situação se empenhará em mostrar que, a sua administração ou governo vem promovendo um mundo atual bom e que caso tenha oportunidade de permanecer no poder, poderá promover ainda mais benefícios, gerando um mundo futuro ainda melhor. Por sua vez, a oposição tentará mostrar que a administração ou governo atual não tem sido capaz de garantir um mundo atual bom e que; se o candidato tiver a oportunidade de vencer a disputa, promoverá os benefícios que a situação não está sabendo entregar aos cidadãos. 
VEIGA, L.; SOUZA, N.R.; CERVI, E.U. As estratégias de retórica na disputa pela prefeitura...

Atrás desse desenho de retórica há a percepção de que os eleitores agem de maneira a maximizar suas oportunidades e reduzir os seus custos de informação. Ou seja, o eleitor imaginará o mundo futuro que cada um dos principais candidatos na disputa poderá lhe oferecer caso eleito.

A construção da expectativa do mundo futuro de cada candidato se dá a partir da avaliação que os eleitores fazem do mundo atual. Aquele candidato que apresentar um mundo futuro melhor terá mais chances de vencer as eleições. No entanto, a construção dos mundos não pode ser descolada da realidade. Os mundos atuais e futuros devem parecer verossímeis.

Em seu trabalho, Figueiredo et al (2000) apresentam recursos discursivos que são típicos da situação e outros que são pertinentes para a oposição. Os mandatários utilizam estratégias como o carisma e o cargo, competência e o cargo, símbolos do cargo, postura "acima da briga", ênfase em realizações e associação com a administração em curso. Já as estratégias do desafiante seriam o apelo à mudança, ofensiva quanto a temas, ênfase no otimismo para o futuro, ataques à administração em curso e ataques ao adversário.

A partir da metodologia desenvolvida por Figueiredo et al (2000) para avaliação das retóricas de campanhas, iremos elaborar a nossa análise sobre a importância do segundo eixo: situação e oposição.

\section{Análise da retórica}

Para a análise dos discursos das campanhas foram utilizados todos os programas de TV e spots veiculados pelas campanhas de Marta Suplicy e José Serra na disputa municipal de 2004. As gravações foram disponibilizadas pelo Laboratório de Comunicação Política e Opinião Pública Doxa/IUPERJ.

A análise dos programas se deu a partir de uma planilha fortemente inspirada na metodologia desenvolvida por Figueiredo et al (2000). Poucas alterações foram feitas, apenas o que era necessário para adaptar uma planilha originalmente feita para análises de spots, para um estudo que incluía também o programa de TV.

O grupo de pesquisadores composto por professores e bolsistas de iniciação científica se reuniu para o pré-teste da planilha e para o treinamento da coleta de dados. A intenção com o treinamento era discutir e esclarecer dúvidas sobre a identificação das diversas categorias e sua aplicação. Feito isso, um grupo de apenas três pesquisadores (uma professora e duas bolsistas) ficou responsável pela aplicação das planilhas. O pequeno grupo estabeleceu freqüente interlocução durante a coleta dos dados. 
Os resultados serão apresentados na tabela a partir das unidadessegmentos e tempo em segundos. A unidade-segmento é definida a partir das variáveis imagem e tema. Conta-se um novo segmento sempre que há alteração de tema ou de imagem.

\subsection{Avaliação do eixo esquerda - direita.}

A partir da análise de conteúdo das mensagens é possível perceber como cada campanha se posicionou diante das três clivagens.

Clivagem neoliberalismo e intervenção estatal: 0 assunto não foi abordado pelas campanhas de Marta Suplicy e de José Serra. Embora o desemprego aparecesse nas pesquisas de opinião como um dos três maiores problemas da capital, os candidatos não discursaram sobre os efeitos da política econômica no índice de desemprego, por exemplo. Mas os candidatos mais à esquerda do PT elaboraram ataques ao "PSDB de Serra e do ex-presidente Fernando Henrique" e ao "PT de Marta e do presidente Lula". A ex-prefeita e candidata Luiza Erundina em sua propaganda chegou a perguntar por que Marta e Serra não tocavam no assunto desemprego em São Paulo. A resposta vinha a seguir: porque a política econômica de Lula era a mesma de FHC e ambas geraram e continuam gerando o desemprego.

Clivagem igualdade social: Marta Suplicy se empenhou em esclarecer que em sua administração a prioridade fora e continuaria sendo a classe mais baixa da população de São Paulo, a que mais precisava de amparo da administração. Enquanto Marta falava sobre tal prioridade abertamente, José Serra preferia propor que a sua gestão seria para toda cidade. No entanto, ao apresentar suas realizações enquanto ministro, gostava de mostrar como já havia provido saúde para a população de classe mais baixa. Desta forma, as duas campanhas - uma de maneira mais explícita e outra de maneira mais implícita - mostraram preocupação e capacidade de prover maior bem estar social para o povo mais carente.

Como era de se esperar, as campanhas se comportaram de maneira muito próximas quando envolviam a questão da igualdade e dos direitos sociais. Afinal, como Singer (2002) propôs, se trata de uma ideologia nacional.

Clivagem participação popular: Os dois candidatos se preocuparam em demonstrar que uma vez eleitos garantiriam bem estar social para os seus moradores. Curioso, no entanto, foi a maneira como propunham realizar tal projeto. Apresentavam-se como grandes líderes capazes de prover benefícios ao povo. Não deixavam claro se falavam de direitos ou de favores. Neste caso, os candidatos se aproximavam mais do discurso aqui classificado como direita do que de esquerda. As campanhas não enfatizaram a 'participação popular'.

Depoimento de Marta Suplicy em seu programa eleitoral ainda no primeiro turno: 
VEIGA, L.; SOUZA, N.R.; CERVI, E.U. As estratégias de retórica na disputa pela prefeitura...

"Mas para ser sincera, eu vou confessar para vocês, que em alguns momentos eu sinto um aperto no coração. Eu jamais vou poder esquecer de uma senhora de 70 anos, moradora da Zona Leste. Ela me disse que tinha brigado, brigado feio, com uma vizinha por minha causa. Ela me disse indignada: "Prefeita, ela recebe o Renda Mínima, sua filha estuda no Céu, ela tem um retrato da senhora no quarto dela e ela votou no Serra! Escondido da filha!" Olha confesso que eu tomei um susto. Eu tentei acalmar a senhora, dizendo: "É isso mesmo são coisas da vida. Cada um tem o direito de fazer o que quiser, de votar em quem quiser". Mas ela insistiu repetindo: "Direito ela tem, mas isso não é justo". Na verdade, eu saí dali com a sensação de que não só não consegui convencer ela com meus argumentos, como o contrário, foi ela que mexeu comigo de verdade com o seu não é justo.Durante o resto do dia, volta e meia, aquele pensamento vinha na cabeça.(...) Ainda há tempo, minha amiga. Pare, pense, reflita sobre tudo isso e principalmente consulte seu coração. Será que depois de tudo que eu fiz será justo não me dar a oportunidade para concluir tudo o que comecei?

Programa de José Serra, dia 27 de outubro de 2004.

Locutor em off: A dona Maria recebeu uma carta do Ministro logo depois de sofrer um infarto.

Dona Maria: Tem vez que eu estou deitada assim e fico pensando: "Meu Deus do Céu, como é que eu fui receber uma benção tão grande logo do Ministro José Serra? É uma lembrança que eu trago comigo, é a carta dele".

Depoimento de José Serra sobre a saúde.

A edição dos programas com depoimentos de populares reforçava a imagem da autoridade do candidato José Serra diante do povo. Ao mesmo tempo em que os eleitores apresentavam uma postura ativa ao manifestarem desafios do seu dia-adia, eles agradeciam veementemente o político por suas realizações. Nestes momentos eles pareciam "orbitar" ao redor do candidato.

Programa de José Serra, dia 28 de outubro de 2004. 
Locutor em off: Serra comanda campanhas de Saúde que melhoraram a vida de milhões de pessoas. Mutirão da catarata: Mais de 700 mil cirurgias.

Povo fala: Estou aqui vendo o mundo que eu não via.

Locutor em off: Campanha da próstata salvou a vida do seu Maneco.

Seu Maneco: Sou muito grato ao seu José Serra. É uma coisa que eu vou ficar devendo para ele o resto da vida. A coisa mais importante da vida é a saúde.

Depoimento de José Serra sobre a saúde.

As passagens lembram a análise de Albuquerque (1999) sobre como os candidatos Fernando Collor de Mello e Luiz Inácio Lula da Silva se relacionavam com a massa em suas campanhas de 1989. De acordo com Albuquerque, nos programas dos dois candidatos, havia uma presença maciça de pessoas do povo. No entanto, o tratamento dado em cada programa era distinto. As cenas de campanha dos programas de Collor enfatizavam, sobretudo, a autoridade e o heroísmo do candidato. Já na campanha de Lula, as cenas, em vez de acentuar a atuação do candidato, destacavam a participação da massa, composta por grande número de trabalhadores organizados.

Não há como identificar porque as campanhas tomaram uma postura tão distante do que se poderia esperar dos dois partidos mencionados freqüentemente como mais urbanos e modernos do país. Sabemos que isso não foi uma tendência do PT em todo o país. A campanha de Raul Pont em Porto Alegre foi profundamente ideológica. O candidato defendia com afinco a mobilização popular, citando as realizações do orçamento participativo na capital gaúcha. Existe, no entanto, uma suspeita que deve ser levantada. Desde 1988, a disputa em São Paulo vinha sendo polarizada entre o petismo e o malufismo. O pleito de 2004 vinha apresentando um novo jogo e as forças em disputa precisavam conquistar os "órfãos" do malufismo. 
VEIGA, L.; SOUZA, N.R.; CERVI, E.U. As estratégias de retórica na disputa pela prefeitura...

4.2) Avaliação do eixo situação - oposição.

Em relação a esse eixo, os dois candidatos assumiram as posturas esperadas: Marta assumiu um discurso de situação e José Serra, o de oposição. Como já foi mencionado anteriormente, os candidatos priorizaram o apelo pragmático, focando seus discursos em proposições que poderiam facilitar o discurso racional. O quadro a seguir apresenta as principais linhas das estratégias discursivas:

\section{Quadro1: Estratégias de retórica}

\begin{tabular}{|c|c|c|}
\hline Interpretação & José Serra- PSDB & Marta Suplicy- PT \\
\hline Mundo atual & $\begin{array}{l}\text { A administração atual não sabe } \\
\text { planejar e priorizar o que de fato é } \\
\text { importante. Ela deixou a desejar, } \\
\text { particularmente na área da saúde. } \\
\text { "Não é possível que se tenha } \\
\text { dinheiro para túnel e não tenha para } \\
\text { colocar médicos nos postos de } \\
\text { saúde, que se gaste com coqueiro e } \\
\text { não se gaste com remédio." } \\
\text { Argumento de José Serra. }\end{array}$ & $\begin{array}{l}\text { A cidade melhorou muito com a } \\
\text { atual administração. Marta ao } \\
\text { assumir a Prefeitura de São } \\
\text { Paulo se deparou com a herança } \\
\text { maldita: caos no transporte } \\
\text { público e escolas municipais de } \\
\text { lata. Hoje: Renovação da frota de } \\
\text { ônibus, Passa Rápido, Bilhete } \\
\text { Único e Céus. Revitalização de } \\
\text { parte da cidade. }\end{array}$ \\
\hline Mundo futuro & $\begin{array}{c}\text { Dar continuidade aos bons projetos } \\
\text { da atual gestão e fazer o que foi } \\
\text { negligenciado pela atual } \\
\text { administração. Prioridade para a } \\
\text { saúde: criação do "mãe paulistana", } \\
\text { mutirão da saúde com consultas } \\
\text { especializadas e exames, } \\
\text { abastecimento dos postos com } \\
\text { remédios. Integração do transporte } \\
\text { (ônibus/metrô). Manter e ampliar o } \\
\text { projeto renda mínima. Construir } \\
\text { mais moradias através do } \\
\text { planejamento conjunto da } \\
\text { Cohab(prefeitura) e Cdhu (governo). } \\
\text { Manter os Céus educação e ampliar } \\
\text { as vagas das creches e pré-escolas. } \\
\text { Acabar com as escolas de lata. }\end{array}$ & $\begin{array}{c}\text { Continuar e ampliar os projetos } \\
\text { nas áreas de educação, } \\
\text { transporte e planejamento } \\
\text { urbano (mais Céus e mais Passa } \\
\text { Rápido), mas a prioridade será a } \\
\text { saúde. Criação do "Céu saúde". }\end{array}$ \\
\hline
\end{tabular}




\begin{tabular}{|c|c|c|}
\hline O que fazer & $\begin{array}{l}\text { "Trabalhar desde o primeiro dia de } \\
\text { governo". } \\
\text { União dos governos municipal e } \\
\text { estadual. "Geraldo e Serra juntos, } \\
\text { competência em dobro". } \\
\text { "Trabalhando juntos em favor da } \\
\text { nossa cidade". }\end{array}$ & $\begin{array}{c}\text { União da Prefeitura com o } \\
\text { Governo Federal. }\end{array}$ \\
\hline Garantia & $\begin{array}{l}\text { Personalismo: Nasceu em uma casa } \\
\text { simples na Mooca, de família } \\
\text { humilde, estudou em escolas } \\
\text { públicas e foi professor. } \\
\text { Sua trajetória política: Secretário do } \\
\text { Planejamento governo Franco } \\
\text { Montoro, duas vezes Deputado } \\
\text { Federal, Senador, Ministro do } \\
\text { Planejamento e Ministro da Saúde. } \\
\text { Escolhido melhor Ministro da Saúde } \\
\text { do Brasil. Criou o seguro- } \\
\text { desemprego. } \\
\text { Grupo político: Trânsito político, } \\
\text { proximidade com o Governo } \\
\text { Estadual. }\end{array}$ & $\begin{array}{c}\text { Personalismo. Mulher de } \\
\text { coragem: enfrentou a máfia do } \\
\text { transporte. } \\
\text { Experiência administrativa: } \\
\text { acabou com a máfia dos } \\
\text { transportes, construiu os CEUs } \\
\text { educação, revitalizou o Mercado } \\
\text { Municipal, ruas e avenidas da } \\
\text { cidade. } \\
\text { Grupo político: Acesso ao } \\
\text { governo federal. }\end{array}$ \\
\hline
\end{tabular}

\subsection{1) O mundo atual}

De acordo com o mundo atual de Serra, a administração de Marta estava deixando a desejar, pois havia descuidado de áreas importantes da administração. O tucano mostrava o desempenho da prefeita na área da saúde para testar a ineficiência de sua gestão.

Marta para se defender lembrava que pegara uma prefeitura falida, com péssimos sistemas de transporte e de educação e que ao longo dos últimos quatro anos havia feito muito pela cidade.

Os discursos de Serra e Marta estavam de alguma forma atrelados à realidade, mas a argumentação de José Serra era capaz de reproduzir melhor o grau satisfação dos eleitores. No mundo real, a prefeita Marta era avaliada predominantemente de maneira regular. De acordo com pesquisa Ibope realizada no período pré-eleitoral, em junho de $2004,40,8 \%$ dos paulistanos achavam que a sua administração estava regular. Também eram altas as avaliações péssima $(23,8 \%)$ e ruim $(11,06 \%)$, e para as avaliações positivas por outro lado, eram: boa $21,5 \%$ e ótima $(2,3 \%)$. 
VEIGA, L.; SOUZA, N.R.; CERVI, E.U. As estratégias de retórica na disputa pela prefeitura...

Ainda de acordo com a pesquisa Ibope, a insatisfação com a gestão era justificada em boa parte pela péssima avaliação do serviço da saúde (nota média $3,77)$. Para $59,8 \%$ dos moradores, o serviço de saúde era um dos três principais problemas, ao lado do desemprego (66\%) e da segurança pública (47,5\%). Desta forma, quando o candidato tucano buscava construir um mundo atual ruim, ele apontava para o caos na saúde.

O discurso de defesa de Marta Suplicy também estava baseado na realidade. No mundo real, a educação e o transporte eram os serviços públicos que despertavam mais satisfação. Destaca-se a satisfação com o projeto Bilhete Único $(7,44)$, que permitia o usuário andar em diferentes veículos ao longo de duas horas com apenas um bilhete. Na área da educação, destaca-se o contentamento com o CEU's ( 7,28).

Os dados de pesquisas realizadas pelo Instituto Datafolha mostram que José Serra era visto como o candidato mais preparado para ser prefeito e o mais preparado para cuidar da saúde. Já Marta Suplicy era tida como a candidata mais preparada para cuidar da educação e do transporte.

Grupo de Tabelas 1: Opiniões sobre o preparo dos candidatos - Instituto Datafolha (\%)

\begin{tabular}{|c|c|c|c|}
\hline & $\begin{array}{c}24 \mathrm{e} \\
25 / 6 / 2004\end{array}$ & $26 / \& / 2004$ & $17 / 9 / 2004$ \\
\hline \multicolumn{4}{|l|}{$\begin{array}{l}\text { O MAIS PFEPARADO } \\
\text { PARA SER PFEFEITO }\end{array}$} \\
\hline José Serra (PSDB) & 27 & 30 & 37 \\
\hline Marta Suplicy (PT) & 16 & 28 & 29 \\
\hline Paulo Maluf (PP) & 35 & 24 & 17 \\
\hline wiza Erundina (PSB) & 7 & 4 & 3 \\
\hline Todos & 0 & 1 & 0 \\
\hline Nenhum & 4 & 4 & 5 \\
\hline Não sabe & 7 & 7 & 6 \\
\hline \multicolumn{4}{|l|}{$\begin{array}{l}\text { O MAIS PFE PARADO } \\
\text { PARA CUIDAR DA } \\
\text { ÁRE A DA SAÍDE }\end{array}$} \\
\hline José Serra (PSDB) & 60 & 62 & 61 \\
\hline Marta Suplicy (PT) & 6 & 13 & 18 \\
\hline Paulo Maluf (PP) & 14 & 9 & 7 \\
\hline wiza Erundina (PSB) & 5 & 3 & 2 \\
\hline Todos & 0 & 0 & 0 \\
\hline Nenhum & 4 & 3 & 5 \\
\hline Não sabe & 8 & 7 & 6 \\
\hline
\end{tabular}

\begin{tabular}{|c|c|c|c|}
\hline & $\begin{array}{c}24 \mathrm{e} \\
25 / 6 / 2004\end{array}$ & $26 / 8 / 2004$ & $17 / 9 / 2004$ \\
\hline \multicolumn{4}{|l|}{$\begin{array}{l}\text { OMAIS PREP ARADO } \\
\text { PARA CUIDAR DA } \\
\text { ÁREA DA EDUCAÇĀO }\end{array}$} \\
\hline Marta Suplicy (PT) & 22 & 37 & $\$$ \\
\hline José Serra (PSDB) & 31 & 26 & 34 \\
\hline Paulo Maluf (PP) & 18 & 12 & 8 \\
\hline wiza Erundina (PSB) & 8 & 6 & 5 \\
\hline Todos & 0 & 0 & 0 \\
\hline Nenhum & 5 & 3 & 5 \\
\hline Não sabe & 11 & 11 & 8 \\
\hline \multicolumn{4}{|l|}{$\begin{array}{l}\text { OMAIS PFEPARADO } \\
\text { PARA C UIDARDA } \\
\text { ÁREA DO TRANSPORTE }\end{array}$} \\
\hline Marta Suplicy (PT) & 28 & 48 & 48 \\
\hline José Serra (PSDB) & 19 & 16 & 23 \\
\hline Paulo Maluf (PP) & 24 & 16 & 13 \\
\hline wiza Erundina (PSB) & 7 & 4 & 2 \\
\hline Todos & 0 & 0 & 0 \\
\hline Nenhum & 4 & 4 & 4 \\
\hline Não sabe & 13 & 11 & 9 \\
\hline
\end{tabular}




\subsubsection{0 mundo futuro}

Nas campanhas, os candidatos não dirigiram muita atenção na construção dos mundos futuros. Como mostra a tabela, falaram mais do passado e do presente do que do futuro.

Tabela 2: Dimensão Temporal

\begin{tabular}{|c|c|c|c|c|c|}
\hline \multirow{2}{*}{ Candidato } & Dimensão & $\begin{array}{c}\text { n. } \\
\text { segmentos }\end{array}$ & $\begin{array}{c}\% \\
\text { segmentos }\end{array}$ & $\begin{array}{c}\text { n. } \\
\text { segundos }\end{array}$ & $\begin{array}{c}\% \\
\text { segundos }\end{array}$ \\
\hline \multirow{4}{*}{ José Serra } & Passado e presente & 534 & 74,2 & 6428 & 65,10 \\
\cline { 2 - 6 } & Futuro & 180 & 25 & 3350 & 33,93 \\
\cline { 2 - 6 } & Indefinido & 6 & 0,8 & 96 & 0,97 \\
\cline { 2 - 6 } & Total & 740 & 100 & 9874 & 100 \\
\hline \multirow{3}{*}{ Marta Suplicy } & Passado e presente & 447 & 80,7 & 7327 & 82,46 \\
\cline { 2 - 6 } & Futuro & 105 & 19 & 1539 & 17,32 \\
\cline { 2 - 6 } & Indefinido & 2 & 0,4 & 19 & 0,21 \\
\cline { 2 - 6 } & Total & 573 & 100 & 8885 & 100 \\
\hline
\end{tabular}

Os mundos futuros prometidos por José Serra e Marta Suplicy eram muito parecidos. José Serra propunha continuar o que estava dando certo e dar prioridade para a saúde, que havia sido abandonada na gestão de Marta. Já a então prefeita argumentava que não apenas manteria, mas também expandiria os projetos de sucesso de sua gestão e daria prioridade para a saúde.

É preciso destacar que embora as interpretações do PT e do PSDB sobre o mundo atual resultassem em versões diferentes, ao proporem o mundo futuro, os projetos apresentados pelas campanhas ficavam semelhantes, e o que Marta chamava de continuidade Serra chamava de mudança.

\subsection{3) A garantia}

Diante de mundos futuros tão parecidos, a garantia passou a ganhar importância na hora da decisão do voto. Na medida em que as diferenças entre os dois planos de governo não ficavam evidentes para o eleitor, este começou a procurar entre Marta e Serra aquele que mais poderia cumprir as suas promessas, uma vez eleito. Ou seja, o eleitor passou a se preocupar com a garantia da entrega das propostas, mais do que com os projetos em si, que thes pareciam muito semelhantes. Com freqüência, o eleitor procura identificar tal garantia nas trajetórias de vida e também política-administrativa dos candidatos, em suas características pessoais e em seu grupo político. 
VEIGA, L.; SOUZA, N.R.; CERVI, E.U. As estratégias de retórica na disputa pela prefeitura...

É possível perceber que os dois candidatos buscaram reforçar a sua imagem na tentativa de conquistar a confiança dos eleitores. As campanhas de Marta Suplicy e José Serra foram surpreendentemente centradas nas imagens dos candidatos. Serra buscava se apresentar como um político experiente, capacitado e do bem, preocupado com as pessoas. A sua experiência vinha de sua trajetória política. Já Marta Suplicy se preocupou em construir uma imagem de prefeita experiente, de coragem, que cumpre o que fala, voltada para os mais pobres.

Tabela 3: Atributo do candidato

\begin{tabular}{|c|c|c|c|c|c|}
\hline Candidato & Atributo & n. segmentos & $\begin{array}{c}\text { \% Val. } \\
\text { segmentos }\end{array}$ & n. segundos & $\begin{array}{c}\% \text { val. } \\
\text { segundos }\end{array}$ \\
\hline \multirow{4}{*}{$\begin{array}{c}\text { José } \\
\text { Serra }\end{array}$} & Pessoal & 54 & 12,2 & 748 & 13,1 \\
\cline { 2 - 6 } & Político & 366 & 82,4 & 4656 & 81,58 \\
\cline { 2 - 6 } & Administrativo & 24 & 5,4 & 303 & 5,31 \\
\cline { 2 - 6 } & Total & 444 & 100 & 5707 & 100 \\
\hline \multirow{3}{*}{$\begin{array}{c}\text { Marta } \\
\text { Suplicy }\end{array}$} & Pessoal & 19 & 7,2 & 345 & 7,79 \\
\cline { 2 - 6 } & Político & 18 & 6,8 & 345 & 7,79 \\
\cline { 2 - 6 } & Administrativo & 228 & 86 & 3737 & 84,41 \\
\cline { 2 - 6 } & Total & 265 & 100 & 4427 & 100 \\
\hline
\end{tabular}

O partido e o grupo político do candidato também podem ser utilizados como garantia em campanhas eleitorais, como já foi mencionado. Ao longo de mais de vinte anos de história, o PT foi apresentado como a garantia da ética e da transparência. Marta Suplicy chegou a utilizar esse recurso no pleito de 2000. Em 2004, o partido não desempenhou este papel. Nem Marta e nem Serra fizeram muitas referências aos partidos.

Tabela 4: Menções ao partido

\begin{tabular}{|c|c|c|c|c|c|}
\hline \multirow{2}{*}{ Candidato } & Menção & $\begin{array}{c}\mathrm{n} . \\
\text { segmentos }\end{array}$ & $\begin{array}{c}\% \\
\text { segmentos }\end{array}$ & $\begin{array}{c}\mathrm{n} . \\
\text { segundos }\end{array}$ & $\begin{array}{c}\% \\
\text { segundos }\end{array}$ \\
\hline \multirow{3}{*}{ José Serra } & Sim & 3 & 0,5 & 62 & 0,60 \\
\cline { 2 - 6 } & Não & 737 & 99,6 & 10196 & 99,4 \\
\cline { 2 - 6 } & Total & 740 & 100 & 10258 & 100 \\
\hline \multirow{3}{*}{ Marta Suplicy } & Sim & 3 & 0,5 & 116 & 1,26 \\
\cline { 2 - 6 } & Não & 570 & 99,5 & 9115 & 88,86 \\
\cline { 2 - 6 } & Total & 573 & 100 & 9231 & 100 \\
\hline
\end{tabular}


Mas algumas lideranças foram escolhidas e serviram para transmitir a idéia de força política e apoio dos partidos aos candidatos. A campanha de José Serra contava com o patrono Geraldo Alckmin, governador do estado. Já Marta contava com o presidente Lula como patrono. De acordo com pesquisa Ibope, naquele momento, o patrono de José Serra agregava mais prestígio do que o patrono de Marta Suplicy.

Tabela 5: Avaliação de governos - Pesquisa Ibope (junho/2004)

\begin{tabular}{|c|c|c|}
\hline Avaliação & Governo Estadual & Governo Federal \\
\hline Ótima & 9 & 3 \\
\hline Boa & 35 & 22 \\
\hline Regular & 41 & 39 \\
\hline Ruim & 4 & 11 \\
\hline Péssima & 8 & 22 \\
\hline NS & 2 & 1 \\
\hline
\end{tabular}

Marta Suplicy apresentou ainda outras lideranças em seu programa: os senadores Aloísio Mercadante e Eduardo Suplicy e o Ministro da Fazenda, Antônio Palocci. Em todas aparições, o objetivo das mensagens era mostrar que a prefeita Marta poderia contar com o apoio do governo federal em suas realizações futuras. Desta forma, percebe-se que mais do que lideranças partidárias, as lideranças se apresentavam e agiam como operadores do governo federal. Exceção para o senador Suplicy, cuja presença teve uma motivação mais familiar do que política.

Tabela 6: Apelo e endosso de patronos.

Serra (governador Geraldo Alckmin); Marta (presidente Lula) - e lideranças.

\begin{tabular}{|c|c|c|c|c|c|}
\hline Candidato - endosso & Apelo & $\begin{array}{c}\mathrm{n} . \\
\text { segmentos }\end{array}$ & $\begin{array}{c}\% \\
\text { segmentos }\end{array}$ & $\begin{array}{c}\mathrm{n} . \\
\text { segundos }\end{array}$ & $\begin{array}{c}\% \\
\text { segundos }\end{array}$ \\
\hline \multirow{4}{*}{ José Serra - patrono } & Pragmático & 17 & 60,7 & 218 & 56,48 \\
\cline { 2 - 6 } & Político & 4 & 14,3 & 76 & 19,69 \\
\cline { 2 - 6 } & Emocional & 7 & 25 & 92 & 23,83 \\
\cline { 2 - 6 } & Total & 28 & 100 & 386 & 100 \\
\hline \multirow{4}{*}{ Marta Suplicy - patrono } & Pragmático & 10 & 50 & 435 & 61,27 \\
\cline { 2 - 6 } & Político & 5 & 25 & 193 & 27,18 \\
\cline { 2 - 6 } & Emocional & 4 & 20 & 59 & 8,31 \\
\cline { 2 - 6 } & Documental & 1 & 5 & 23 & 3,24 \\
\cline { 2 - 6 } & Total & 20 & 100 & 710 & 100 \\
\hline
\end{tabular}


VEIGA, L.; SOUZA, N.R.; CERVI, E.U. As estratégias de retórica na disputa pela prefeitura...

\begin{tabular}{|c|c|c|c|c|c|}
\hline Candidato - endosso & Apelo & $\begin{array}{c}\mathrm{n} . \\
\text { segmentos }\end{array}$ & $\begin{array}{c}\% \\
\text { segmentos }\end{array}$ & $\begin{array}{c}\mathrm{n} . \\
\text { segundos }\end{array}$ & $\begin{array}{c}\% \\
\text { segundos }\end{array}$ \\
\hline \multirow{3}{*}{$\begin{array}{c}\text { Marta Suplicy - } \\
\text { lideranças partidárias }\end{array}$} & Pragmático & 44 & 91 & 777 & 87,5 \\
\cline { 2 - 6 } & Político & 1 & 2,1 & 83 & 9,35 \\
\cline { 2 - 6 } & Emocional & 2 & 4,2 & 18 & 2,03 \\
\cline { 2 - 6 } & Documental & 1 & 2,1 & 10 & 1,13 \\
\cline { 2 - 6 } & Total & 48 & 100 & 888 & 100 \\
\hline
\end{tabular}

Marta Suplicy fez uso do seu cargo em 37,9\% dos fragmentos de sua campanha e fez associação com a sua administração em 58,8\% dos fragmentos. Por isso, podemos verificar que ela usou a estratégia de mandatária.

Por outro lado, de acordo com a literatura internacional, manter a postura acima da briga também é uma atitude de mandatário. Mas, no caso da eleição municipal de São Paulo, mandatária e desafiante tiveram uma postura muito próxima em relação aos ataques.

Tabela 7: Postura "acima da briga"

\begin{tabular}{|c|c|c|c|c|c|}
\hline Candidato & Acima da briga & $\begin{array}{c}\mathrm{n} . \\
\text { segmentos }\end{array}$ & $\begin{array}{c}\% \\
\text { segmentos }\end{array}$ & $\begin{array}{c}\mathrm{n} . \\
\text { segundos }\end{array}$ & $\begin{array}{c}\% \\
\text { segundos }\end{array}$ \\
\hline \multirow{3}{*}{ José Serra } & Sim & 627 & 84,7 & 8379 & 81,68 \\
\cline { 2 - 6 } & Não & 113 & 15,3 & 1879 & 18,32 \\
\cline { 2 - 6 } & Total & 740 & 100 & 10258 & 100 \\
\hline \multirow{3}{*}{ Marta Suplicy } & Sim & 484 & 84,5 & 7869 & 85,25 \\
\cline { 2 - 6 } & Não & 89 & 15,5 & 1362 & 14,75 \\
\cline { 2 - 6 } & Total & 573 & 100 & 9231 & 100 \\
\hline
\end{tabular}

Serra gastou $15,3 \%$ dos seus segmentos com ataques à administração de Marta Suplicy. Os ataques tinham o caráter pragmático e não apontavam para questões ideológicas ou partidárias. Criticava o que a prefeita havia deixado de fazer e responsabilizava a mesma por suas falhas. Cabe constatar que tais ataques eram em sua maioria feitos pelo próprio candidato Serra, contrariando a regra em propaganda eleitoral que prega que os ataques não devem ser realizados pelos próprios candidatos. A fim de preservá-los dos desgastes decorrentes das críticas, tais mensagens tendem a ser transmitidas por outros oradores. No caso específico, Serra assumia o comando dos ataques - em sua maioria voltados para o desempenho da Prefeita na área da saúde - porque gozava da imagem de uma autoridade na questão. Na condição de ex-ministro da Saúde criticava o desempenho da prefeita. Tais críticas acabavam por reforçar ainda mais a sua autoridade. 
Os demais ataques de Serra estavam voltados para a imagem da prefeita Marta. Acusava Marta de ser uma má administradora, sem foco e prioridade nas questões importantes para o povo. Neste caso, o ataque era realizado predominantemente por outros oradores.

Os ataques realizados pela campanha de Marta Suplicy eram realizados por diversos oradores, inclusive pela candidata. Cabe ressaltar a postura de ataque do senador Aloísio Mercadante na campanha.

Tabela 8: Forma do ataque e orador dominante ${ }^{2}$

\begin{tabular}{|c|c|c|c|c|c|}
\hline $\begin{array}{c}\text { Candidato - forma } \\
\text { de ataque }\end{array}$ & Orador dominante & $\begin{array}{c}\mathrm{n} . \\
\text { segmentos }\end{array}$ & $\begin{array}{c}\% \\
\text { segmentos }\end{array}$ & $\begin{array}{c}\mathrm{n} . \\
\text { segundos }\end{array}$ & $\begin{array}{c}\% \\
\text { segundos }\end{array}$ \\
\hline \multirow{4}{*}{$\begin{array}{c}\text { José Serra - } \\
\text { ataque à } \\
\text { administração }\end{array}$} & Candidato & 37 & 90,2 & 768 & 90,89 \\
\hline & $\begin{array}{c}\text { Garoto } \\
\text { propaganda }\end{array}$ & 3 & 7,3 & 57 & 6,75 \\
\hline & Personagem ficção & 1 & 2,4 & 20 & 2,37 \\
\hline & Total & 41 & 100 & 845 & 100 \\
\hline \multirow{7}{*}{$\begin{array}{c}\text { José Serra - } \\
\text { ataque a } \\
\text { adversária }\end{array}$} & Âncora & 17 & 22,7 & 320 & 29,01 \\
\hline & Off locutor & 17 & 22,7 & 226 & 20,49 \\
\hline & Popular & 15 & 20 & 129 & 11,70 \\
\hline & Candidato & 12 & 16 & 212 & 19,22 \\
\hline & $\begin{array}{c}\text { Garoto } \\
\text { propaganda }\end{array}$ & 10 & 13,3 & 143 & 12,96 \\
\hline & Personalidade & 4 & 5,3 & 72 & 6,62 \\
\hline & Total & 75 & 100 & 1103 & 100 \\
\hline \multirow{6}{*}{$\begin{array}{c}\text { Marta Suplicy - } \\
\text { ataque a } \\
\text { adversário }\end{array}$} & Popular & 30 & 33 & 265 & 19,39 \\
\hline & Personalidade & 24 & 26,4 & 431 & 31,53 \\
\hline & Candidato & 19 & 20,9 & 324 & 23,70 \\
\hline & Off locutor & 13 & 14,3 & 236 & 17,26 \\
\hline & $\begin{array}{c}\text { Garoto } \\
\text { propaganda }\end{array}$ & 5 & 5,5 & 111 & 8,12 \\
\hline & Total & 91 & 100 & 1367 & 100 \\
\hline
\end{tabular}

\footnotetext{
2 Algumas explicações sobre a classificação de oradores: candidato (no caso, Marta Suplicy e José Serra), popular (o tradicional "povo fala", "depoimento do homem comum"), personalidades (pessoas que são destaques em suas funções, em geral conhecidas do público: políticos, artistas e esportistas), personagem de ficção, off locutor (locução que narra e descreve imagens diversas), âncora (apresentador principal da campanha, aparece com grande freqüência) e garoto propaganda (apresentadores secundários, que aparecem com menos freqüência, em geral têm participação pontual).
} 
VEIGA, L.; SOUZA, N.R.; CERVI, E.U. As estratégias de retórica na disputa pela prefeitura...

Conclusões

Este estudo buscou identificar continuidades e rupturas no discurso do PT na campanha para a prefeitura de São Paulo em 2004, primeiro pleito em que o partido deixou de ocupar o lugar da oposição nos cenários municipal e nacional. A análise das retóricas desenvolveu-se a partir de dois eixos: ideológico e pragmático.

Em relação ao eixo esquerda e direita, podemos concluir sobre as retóricas analisadas que:

a) O PT não utilizou o discurso contra o neoliberalismo. Evitou tocar no assunto política econômica, tema considerado carro-chefe enquanto o partido estava na oposição nacional. Mas os partidos mais à esquerda se encarregaram das críticas ao modelo neoliberal e agora contra o PSDB e também o PT.

b) Marta Suplicy tentou apresentar-se mais igualitária do que José Serra. Afinado com a ideologia nacional, o tucano também se empenhou em mostrar-se igualitário.

c) O discurso da participação e mobilização popular não esteve presente nas campanhas de Marta Suplicy e de José Serra. Ao contrário, foi possível identificar fragmentos de mensagens nas duas campanhas com tom autoritário e centralizador. Os candidatos foram apresentados em alguns momentos como líderes provedores para uma massa passiva.

Assim, na eleição para prefeitura de São Paulo em 2004, diferente do que ocorreu nos anos anteriores, não houve um discurso típico de esquerda e outro de direita. A análise do eixo ideológico nos leva perceber que as campanhas do PT e do PSDB foram muito semelhantes.

Já ao analisarmos o eixo situação e oposição podemos perceber que cada candidato adotou o comportamento típico de sua situação na disputa:

d) Marta Suplicy descreveu a situação da cidade como sendo boa, mas que poderia melhorar ainda mais e propôs a sua continuidade.

e) José Serra apresentou problemas na cidade e na gestão de Marta Suplicy, responsabilizando a prefeita pelas falhas e não realizações. E em seguida, propunha um mundo futuro diferente.

f) José Serra se empenhou fortemente na criação da imagem de político experiente e Marta Suplicy se empenhou na criação da imagem de prefeita eficiente. Foram campanhas muito personalistas. A garantia estava na imagem.

Os dois candidatos não utilizaram seus partidos como garantia. Esta é outra mudança do discurso do PT que merece ser assinalada. Marta Suplicy contou com o apoio do patrono presidente Lula e dos líderes Antônio Palloci, Aloísio Mercadante e Eduardo Suplicy. Os líderes se apresentavam mais como membros do governo 
federal, dispostos a apoiar Marta Suplicy caso fosse eleita, do que como membros do partido. Serra contou exclusivamente com o seu patrono, o governador Geraldo Alckmin.

O discurso do PT na condição de mandatário foi mais pragmático e menos ideológico; deixou de priorizar o discurso oposicionista ao modelo neoliberal; perdeu a supremacia do discurso sobre a igualdade social e se afastou do apelo pela mudança social a partir da mobilização da sociedade. A adoção do discurso de tom pragmático correspondeu ao que se esperava de um partido de situação: saiu em defesa das suas realizações, fez uso do cargo e associações com a administração. Porém, a campanha não manteve a postura "acima da briga".

Por sua vez, o discurso do PSDB, na condição de desafiante, permaneceu como de costume, mais pragmático e menos ideológico. Assim como antes, o partido não deu ênfase à clivagem liberalismo-intervencionismo. Em relação ao aspecto igualdade social se mostrou tão igualitário quanto 0 PT. E surpreendentemente, assim como aconteceu com Marta Suplicy, José Serra mostrou-se um líder por vezes centralizador e provedor para uma massa necessitada e passiva. O que não era de se esperar dos candidatos dos dois partidos mais modernos de nossa democracia. De acordo com a sua condição de oposição, Serra - na situação de político experiente e ex-ministro da Saúde - fez firmes críticas à gestão e ao desempenho administrativo de Marta Suplicy.

Por fim, cabe uma rápida comparação dos discursos do PT em São Paulo, Curitiba e Porto Alegre. Podemos afirmar que as mudanças de discurso observadas em São Paulo não aconteceram em todo o país. A retórica do PT em Porto Alegre permaneceu com forte conteúdo ideológico, abordando as três clivagens aqui estudadas. Ao mencionar as realizações do partido ao longo de 16 anos à frente da prefeitura, o candidato Raul Pont adotava o slogan pronunciado pelo povo da cidade: "(nome de uma obra ou programa da prefeitura) foi a gente que fez!". Pont, assim como Marta, adotou um discurso pragmático coerente com a sua posição de situação na capital gaúcha.

Já em Curitiba, o PT não deu relevância para o discurso ideológico e adotou uma postura que não condizia com a sua posição na disputa, de oposição. Não atacou a gestão de Cássio Tanigucci (PFL), que tinha como vice-prefeito o seu principal adversário e vencedor da eleição, Beto Richa (PSDB). 
VEIGA, L.; SOUZA, N.R.; CERVI, E.U. As estratégias de retórica na disputa pela prefeitura...

\section{Referências bibliográficas}

ALBUQUERQUE, A. Aqui você vê a verdade na tevê: a propaganda política na televisão. Niterói: Universidade Federal Fluminense, Mestrado em Comunicação, Imagem e Informação, 1999.

AMARAL, R. Em busca do significado das eleições de 1994 (reflexões sujeitas a chuvas e trovoadas). Comunicação \& Política. Nova série, v. 1, n.3, abr-jun, 1995.

BOBBIO, N. Direita e esquerda: razões e significados de uma distinção política. São Paulo: Unesp, 1995.

CHAIA, V.; MENEGUELLO, R.; AZEVEDO, F. e SCHMITT, R. São Paulo: embate partidário, mídia e comportamento eleitoral. In: SILVEIRA, E. (Org) Estratégia, Mídia e Voto. Porto Alegre: Edipucrs, 2002.

FIGUEIREDO, M.; ALDE, A.; DIAS, H. e JORGE, V. Estratégias de Persuasão nas Eleições Majoritárias: Uma proposta metodológica para o estudo da propaganda política. In: FIGUEIREDO, R. (Org.) Marketing Político e Persuasão Eleitoral. São Paulo: Fundação Konrad Adenauer, 2000.

OLIVEIRA, L. A. As estratégias retóricas na construção dos mundos de natureza ficcional da política: um estudo comparativo das campanhas de Belo Horizonte e Salvador na eleição municipal de 2000. Tese de doutorado, Rio de Janeiro, IUPERJ, 2005.

RUBIM, A. Mídia e Política no Brasil. João Pessoa: Editora UFPB, 1999.

SINGER, A. Esquerda e Direita no Eleitorado Brasileiro. São Paulo: Edusp, 2002.

VEIGA, L.F., SOUZA, N. R. e CERVI, E. Da expectativa de vitória à derrota: as estratégias de retórica do PT em Curitiba e Porto Alegre. In: XXIX Encontro da Anpocs, Caxambu, 2005.

VENTURI, G. Imagem Pública, propaganda eleitoral e reeleição na disputa presidencial de 1998. In: Comunicação \& Política, Vol.V, n.3, nova série, set-dez, 1998. 